\title{
Technology And Application On Reservoir Architecture Characterization Based On Sandbodies Spatial Orientation
}

\author{
Zhixin Ma*, Ji Zhang, Wen Xue, Wensheng Wang, Bin Fu, Weifeng Sun, Qianqian Fan, \\ and Ya Li, Sulige Gas Field Research Center of Changqing Oilfield Company, PetroChina, \\ Xi'an, China
}

\begin{abstract}
As the high percent of effective sandbody thickness, the braided river reservoir become to an important exploitation area. The Shihezi group lower $8^{\text {th }}$ section of Sulige gas field is a typical sandy braided river reservoir. Strong reservoir heterogeneity is one of the main restriction factor of gas field development, such as Su X adding area. Referring to the analysis results of modern sedimentary and ancient outcrop configuration, a new reservoir architecture characterize method is presented in this study. The new methods realize river channel sandbody spatial orientation by "changes on bottom of sandbody and microfacies overlay regular pattern", and realize channel bar sandbody spatial orientation by "logging cycle, silt layer position, and microfacies overlay characteristic". The reservoir structure analysis on river channel and channel bar were also carried out, and the effective sandbody control effects by reservoir configuration unit were analyzed. The characterization results show:

1) The two main plane combinations in the single channel sandbody of Shihezi group $8^{\text {th }}$ section in research are: banded channel which width is $1000 \sim 2000 \mathrm{~m}$ and sheet scale channel which width is $1500 \sim 4000 \mathrm{~m}$.

2) The main reservoir configuration units include the channel bar, braided river channel and flood plain. And the channel bar is the main reservoir element.

3) The scales of sandbodies are different due to different genetic type. The thickness of channel bar is $3 \sim 5 \mathrm{~m}$, the width is $250 \sim 300 \mathrm{~m}$, the length is $500 \sim 900 \mathrm{~m}$. The width of braided river channel is less than $200 \mathrm{~m}$. The deposition pattern presents "alternate channel and bar, wide bar and narrow channel" on flat.

4) 5 levels configuration units control the macro distribution of effective sandbodies, four levels configuration unit is the main control factor, 3 levels configuration unit has little effect on the distribution of effective sandbodies.
\end{abstract}

The proposed method has been successfully used on well location optimization in Sulige gas field. It has reference value for the same type of reservoir configuration.

\section{Introduction}

Since the reservoir configuration analysis method was first proposed by Miall in 1985 (Miall 1985), the theory was constantly developed and enriched by sedimentary geologists, and quickly became an important means of accurate reservoir characteristics (especially in the late period of oil and gas reservoirs development). Reservoir architecture refers to the form, scale, direction and their space stack relationships of different reservoir architecture unit and interlayer (Wu 2010; Wu et al. 2008, Wu et al. 2012, Lin et al. 2013). The essence is to study the process of sedimentary environment and the

Copyright $(C$ the author(s). This work is licensed under a Creative Commons Attribution 4.0 International License. 
relationship of sedimentary products, to systematically reveal the characteristics of sedimentary structure and spatial distribution of three-dimensional space, and to characterize its internal macro heterogeneity (Best et al. 2003; Lynds and Hajek 2006; Lunt et al. 2013).

Reservoir configuration analysis begins with observations of paleo outcrops and modern sediments (Miall 1996; Robinson and Mccabe 1997; Liao et al. 1998; Ma et al. 2003). However, the underground reservoir configuration is relatively backward. Nearly for a decade, with the development of ground penetrating radar, loose surface sedimentation and large tank experiments, it was gradually realized that the dimensional fine dissection of the near-surface sedimentary body (Lunt et al. 2013; Robinson et al. 1997; Liao et al. 1998; Ma et al. 2003; Lunt et al. 2004) summed up a lot of prototype models (Best et al. 2003; Lunt et al. 2004; Peakall et al. 2007; Skellya et al. 2003; Ghazi et al. 2009; Corbeanu et al. 2001) and empirical formula (Leeder 1973; Liu and Jiao 1996; Ma and Yang 2000; Ma et al. 2008), and established relevant reservoir quantitative geological knowledge. The progress of near-surface sedimentary body configuration greatly contributes to the development of underground reservoir configuration analysis. Especially in the dense well pattern area, guided by the reservoir prototype model, reference reservoir quantitative geological knowledge base.

The analysis methods of underground reservoir structure were improved, and related research results emerged one after another (Wu et al. 2008, Wu et al. 2012, Lin et al. 2013; Ma et al. 2008; Zhou et al. 2008; Bai et al. 2009; Liu et al. 2011; Li et al. 2011; Zhang et al. 2013). Reservoir structure is covered by sedimentary systems, such as meandering river, delta, alluvial fan (Lin et al. 2013; Jiao et al. 2009; Yi et al. 2010; Wen et al. 2011; Xin 2008).

Although a lot of experimental research work were carried out and some research results were obtained (Best et al. 2003; Lynds and Hajek 2006; Lunt et al. 2013; Liao et al. 1998; Ma et al. 2003; Lunt et al. 2004; Peakall et al. 2007; Skellya et al. 2003; Sun et al. 2014; Bai 2010) with the limitation of well pattern, the braided river underground reservoir structure always focus on single well identification of channel bar sand body. It sometimes cannot accurately predict the distribution of channel bar sandbodies on the plane, which reduces the reliability of braided river reservoir configuration. Take the Shihezi group lower $8^{\text {th }}$ section of Sulige gas field as an example, through the multilevel sandbodies spatial orientation, this paper discusses the method of underground braided river reservoir architecture characterization, to deepen the theory of braided river reservoir configuration and guide the well deployment of the adjacent area.

\section{Geological Features}

The Ordos Basin is a large multi-cycle craton basin. Based on the Archean-Early Proterozoic formation, experienced five sedimentary evolution periods as Aulacogen developed on Middle-late Proterozoic, Shallow sea platform developed on Early Paleozoic, offshore plain developed on Late Paleozoic, inland lake basin developed on Mesozoic, and circumjacent fault depression developed on Cenozoic (He et al. 2003). In the period of whole Late Paleozoic, the Ordos Basin developed Epicontinental Sea, Seaside lake basin and Shallow Sea Platform (Wang et al. 2007). The sedimentary system went through the evolution of Tidal Flat (Lagoon) to Barrier Island developed on Benxi to Taiyuan Period, Lake to Delta developed on Shanxi to Shiqianfeng Period (He et al. 2003; Wen et al. 2007). Sediments have interactive deposit by carbonate rocks, coal seam and terrigenous clastic to terrigenous clastic deposits.

According to the present structural configuration of the basin, combined with the nature of basinal basement, the evolution history of the basin, tectonic development and the structural features, the Ordos basin is divided into six first-order tectonic units with the Yi-shan slope as the main body. Sulige gas field is located in Inner Mongolia Autonomous Region. The structure belongs to Yi-shan slope of the Ordos basin, and exploration area is approximately $3.2 \times 10^{4} \mathrm{~km}^{2}$. It is a large lithologic trap gas reservoir which developed in upper paleozoic coal measures hydrocarbon source beds. The research area is located in the north of the Sulige gas field, bottom-up developed Carboniferous Benxi Formation and Taiyuan Formation, Permian Shanxi Formation, Shihezi Formation and Shiqianfeng Formation during upper Paleozoic. The total sedimentary rock thickness is about $700 \mathrm{~m}$. The Shihezi Formation was divided into eight sections from Shihezi $1^{\text {st }}$ section to Shihezi $8^{\text {th }}$ section (He et al. 2003; Yang et al. 2008). The Shihezi $8^{\text {th }}$ section was further divided into two sub-groups as upper Shihezi $8^{\text {th }}$ section and lower Shihezi $8^{\text {th }}$ section. Large and thick braided channel sandbodies of lower Shihezi $8^{\text {th }}$ section is the main gas layer 
(He et al. 2003; Wen et al. 2007). The average thickness of sandbodies is $30 \sim 40 \mathrm{~m}$. The sandbodies are overlaid and spliced by multi-stage channels, and then classified into four groups.

The target area has been under development since 2008, working area is $13.0 \mathrm{~km}^{2}$. Figure 1 shows a map of the study area. There are 50 gas wells in the area, and average well spacing is $350 \sim 500 \mathrm{~m}$. The well spacing in the area is the largest in Sulige Gas Field at present. There are sufficient dynamic information and data so it is suitable to carry out reservoir structure research in this area.

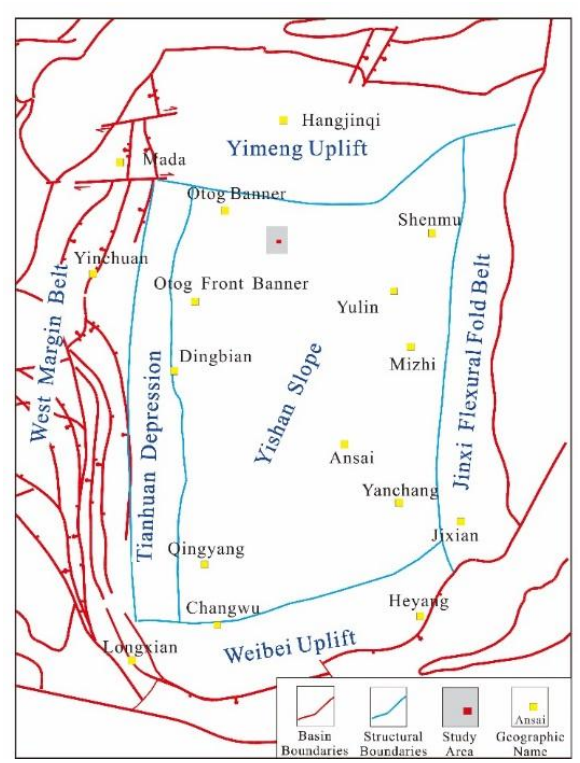

Figure 1-Location of the research area.

Lithologic Features. The study area of lower Shihezi $8^{\text {th }}$ section is a braided river sedimentary system in the background of seasonal arid climate (Chen et al 2008; Li and Yang 2009), and is the main producing formation. During the depositional period, the tectonic activity was stable and the material supply was sufficient (Wang et al 2007), the water was extensive, and the riverstream changed frequently. Macroscopic depositional characteristics show "sand pack mud". Lithology mainly composes of medium sandstone to gritstone ( $\mathrm{Li}$ and Yang 2009). In addition, mineral composition is mainly composed of quartz and cuttings. Quartz content is generally between $45 \sim 85 \%$, cuttings content is between $2.0 \sim 42.6 \%$, feldspar contents is quite small (Wen et al. 2007).

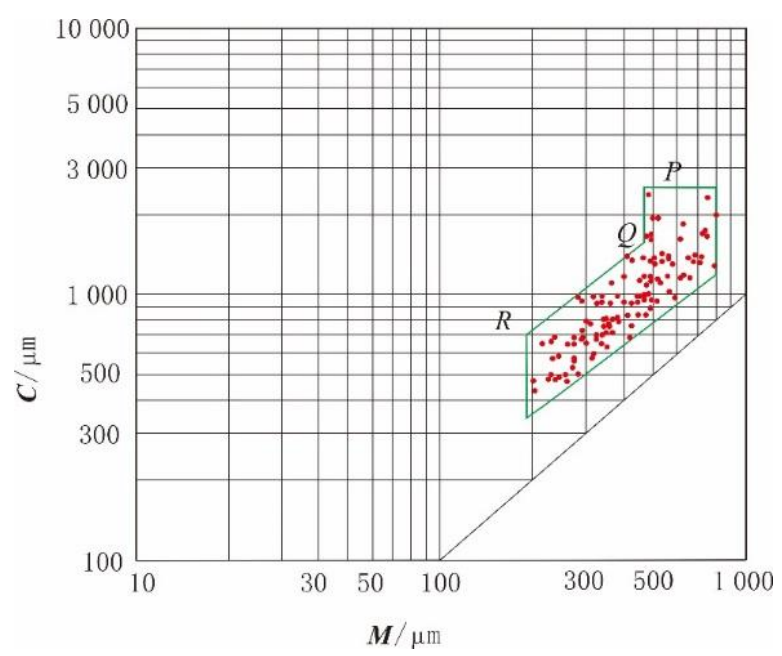

Figure 2-C-M figure of lower Shihezi $8^{\text {th }}$ sandbodies in study area.

Particle Size Characteristics. Observation of core slice microscope and particle size analysis present that, the lithology of lower Shihezi $8^{\text {th }}$ section mainly consists of medium sandstone to gritstone, followed by fine sand, mud, gravel, and silt. Moreover, near-provenance sedimentary characteristics are obvious 
(Wen et al. 2007). Main particle size of sandbodies is $0.4 \sim 1.0 \mathrm{~mm}$. Most of particle size is coarse. The probability curve of particle size is mainly two-stage style, the size classification is bad, mainly is composed of saltation population, followed by rolling population (Yin et al. 2006). In the C-M figure (Figure 2), Q-R stage is well developed and P-Q stage is not developed. This indicates that although the hydrodynamic conditions in the study area are strong, deposition rate is fast, the sediments classification and transformation was bad.

Sedimentary Structure. Sedimentary structure of Shihezi $8^{\text {th }}$ section is various (Wen et al 2007), developed through cross bedding, tabular cross bedding, and parallel bedding (Figure 3). The bottom of sandbodies always present scour surface and partial boulder clay, which reflects strong hydrodynamic conditions. The top of sandbodies constantly present horizontal bedding and ripple cross lamination.

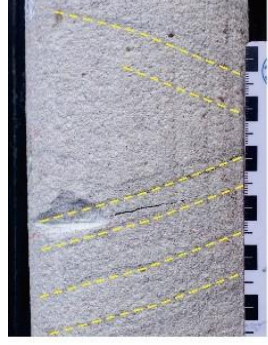

(a) Trouth Cross Bedding

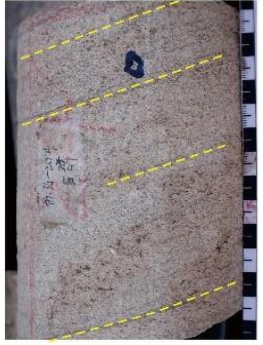

(b) Parallel Bedding

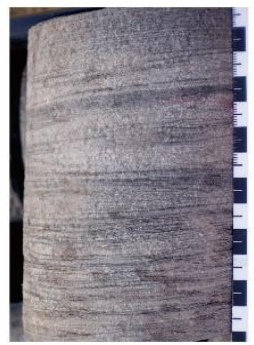

(c)Ripple lamination

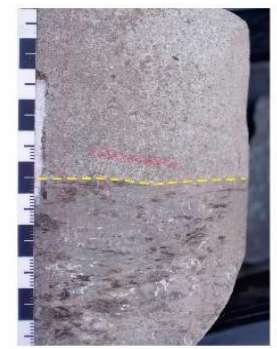

(d) Scour Surfcac

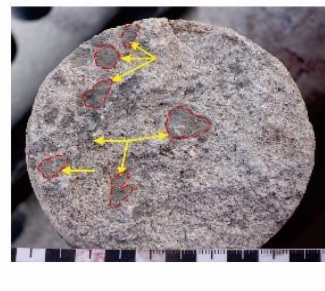

(e)Mud Gravel

Figure 3-Typical braided river sedimentary structure.

\section{Multi-level Sandbody Configuration}

Braided River Sand Body Configuration Level Division. The study is based on Miall's and Wu et al.'s configuration classification scheme (Miall 1985; Wu et al. 2013). The $0^{\text {th }}$ grade is inner laminated interface, $1^{\text {st }}$ grade is laminated interface, $2^{\text {nd }}$ grade interleaving layer interface, $3^{\text {rd }}$ grade is large reapplication or accretion interface by large bottom interface, $4^{\text {th }}$ grade is equivalent to the top and bottom of the large bottom interface, and the $5^{\text {th }}$ grade is top and bottom of the single channel sandbodies. The $0^{\text {th }}$ grade to $5^{\text {th }}$ grade interfaces belong to the classification of lithological configurations (Wu 2010), and the $6^{\text {th }}$ grade interface is single, which represents the beginning or the end of a flood plant. This paper emphasizes the representation of the $4^{\text {th }}$ grade and $5^{\text {th }}$ grade interfaces (single sandbody, single channel) configurationally units distribution.

Characteristics of Configuration Units. Coring well analysis shows that the study area is mainly developed four kinds of configuration units, including channel bar, braided stream, flood plain, and interchannel.

Channel Bar. The channel bar is a main elements of braided river sediments (Yin et al. 2007), formed by sandbodies vertical superposition in several flood events. Lithology mainly is composed of medium sandstone to gritstone. Well logging curve presents "box" type. Both trough cross bedding and tabular cross bedding were developed.

Braided Stream. Braided stream is perennial channel of braided river. Its lithology mainly is composed of medium to fine sandstone. Well logging curve presents a "bell-shape" type, miniature trough cross bedding was developed. The plane forms are interwoven and narrow bands, the profile is top flat and bottom convex. The filling types of braided stream are sand filling, half-sand filling, and mud filling (Sun et al. 2014; Xing 2014).

Flood Plain. Flood plain is distributed at the top of channel. The rocks present gray, sandy brown, brown and black. Lithology mainly consists of mud to silty mudstone, mainly develops horizontal bedding. The thickness changes from several centimeters to tens of centimeters and partial absence. The well logging curve shows high GR value.

Interchannel. The interchannel always develops at the both side of river. The lithology characteristic is mud packed thin sandstone. The stone color, sedimentary structure and logging characteristics are similar as flood plain, and the thickness almost equals to channel sedimentary. 
Interface Recognition of Single Well Configuration. Interface recognition of single well configuration is the key of reservoir depositional periods division (Lin et al. 2013). The lower Shihezi $8^{\text {th }}$ section formations are several periods of overlayed composite sandbodies which were crosscut by flush seriously. As a result, it is difficult to identify the configuration interface. Fine core observation shows that there is a thin residual muddy compartment, and obvious flush contact relationship with a new period of channel over it, which can be marked as one of the $5^{\text {th }}$ level interface identification. Mica clastic vertical occurrence is very common, the hydrodynamic conditions was weakened on the last time of single depositional stage. Mica clastic that is hard to deposit in flood period would appear as large numbers, in accordance with the phenomenon. The $5^{\text {th }}$ level configuration interface would be identified and to be recognized as the $4^{\text {th }}$ level interface by the constraint of $5^{\text {th }}$ level.

\section{Single Channel Sandbody Levels Configuration Anatomy}

Single Channel Sandbodies Spatial Orientation. Various methods of channel boundary recognition, such as interchannel deposition method, top sand elevation method (Wu 2010; Lin et al. 2013; Chen et al. 2004), were used in single channel recognition. Besides, this study proposed a new method, called "changes on bottom of sandbody and microfacies overlay regular pattern", to confirm single channel boundary, and to characterize spatial orientation. The basic principles are as follows (Figure 4).

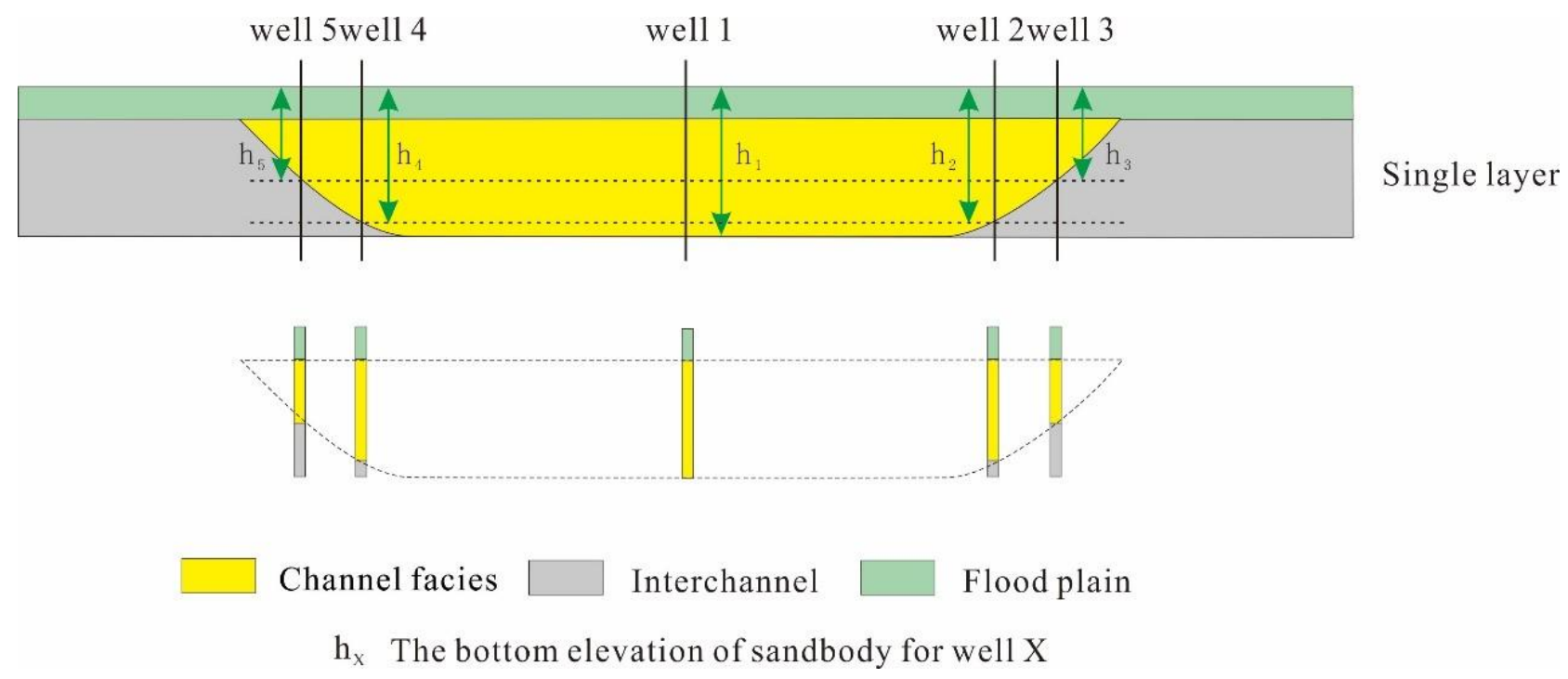

Figure 4-Identify single river schematic.

Single Channel Sandbodies Configuration Characteristics. Based on precise positioning of space, single channel sandbody can be accurately characterized. The results show that the single channel sandbody of lower Shihezi formation $8^{\text {th }}$ section reservoir in SuX encryption area has two main plane combinations: banded single channel and sheet scale single channel (Figure 5). 


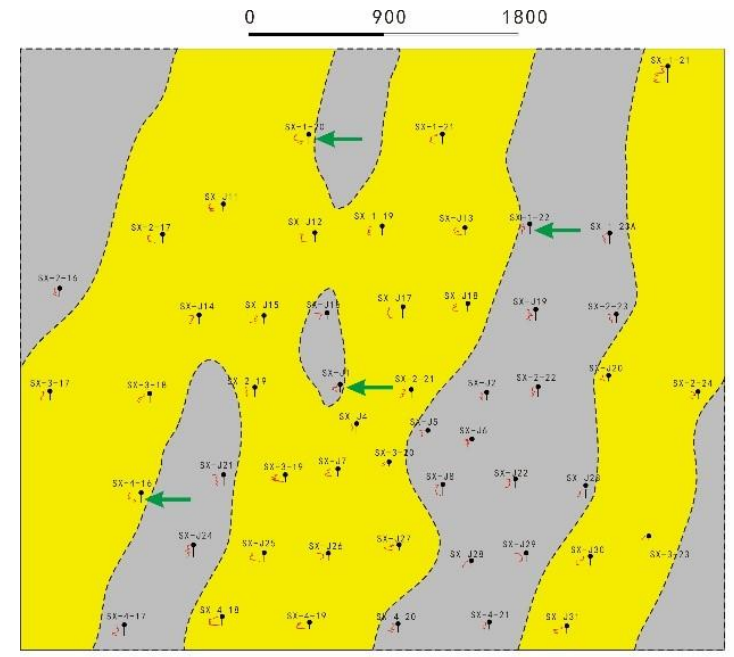

(a) Banded Channel

Channel

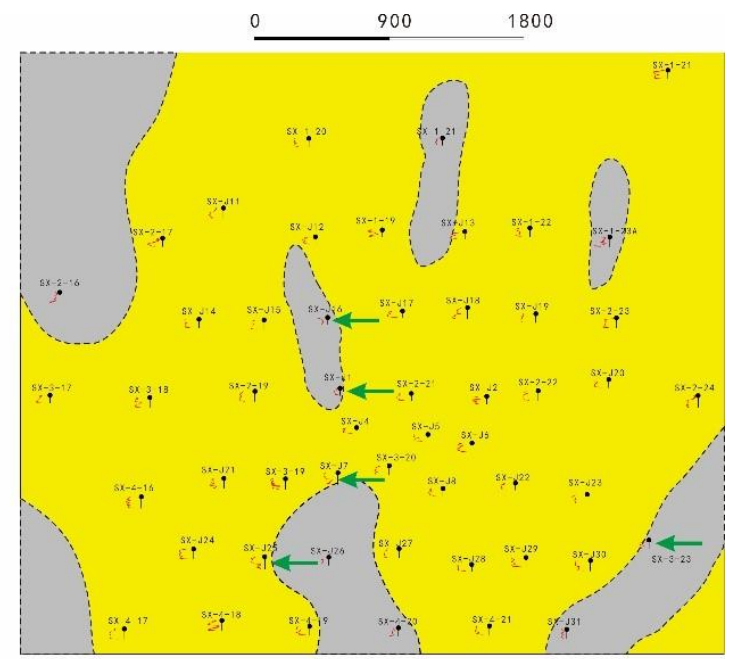

(b) Sheet Scale Channel

Interchannel $\longleftarrow$ Boundary Location Well

Figure 5-Plane configuration unit of single channel sandbody.

Banded Single Channel. Banded single channel mainly develops in formation 2-1 and 2-2 of lower Shihezi $8^{\text {th }}$ section. The single channels are narrow stripes that are isolated and distributed between the river mudstone. This combination is the result of lower horizontal plane, less supply deposition, a single channel lateral migration capacity. The width of banded single channel is $1000 \sim 2000 \mathrm{~m}$.

Sheet Scale Single Channel. Sheet scale single channel mainly developed in formation 2-3, 2-2, 1-3, 1-2 of lower Shihezi $8^{\text {th }}$ section. The single river is in a sheet distribution, and the mudstone between the rivers is not developed. This combination results from higher horizontal plane, enough supply deposition, frequent single channel migration or several single channel intertwining and cutting. The width of sheet scale single channel is $1500 \sim 4000 \mathrm{~m}$.

\section{Anatomical Profile of Single Sandbody}

Spatial Orientation Symbol of Channel Bar Sandbodies. Internal channel bar develops mud interlayer (silt layer), vertical positive rhythm is not obvious, SP and GR logging curves are "box" type. Braided waterways are mostly bell-shaped, showing obvious positive rhythm, and interlayers are not developed.

Logging Curve Morphology. The sedimentation of the channel bar is mainly based on the vertical accretion and downstream accretion. Hydrodynamic of upstream face is strong, and weak in negative side water, resulting in the sediment particle size of single accretion layer turning from coarse to fine. Because of downstream accretion, accretion layer is developed later and keep moving to downstream. Therefore, the particle of upstream face changes a little, the logging curve mainly presents a box style. There is a tendency to thicken up at the retral part, the logging curve mainly presents infundibular. It is possible to estimate the approximate location of channel bar in a single well (Figure 6).

Silt Layer Development Location. Modern channel bar of braided river shows that, hydrodynamic of upstream face is strong, sediment particle size is coarse. The silt layer is always developed at the negative side of river and the side with weak hydrodynamic (Figure 6). This provides direct evidence to identify the location of channel bar. If a well is drilled to a silt layer, the approximate position can be forecasted (Figure 7).

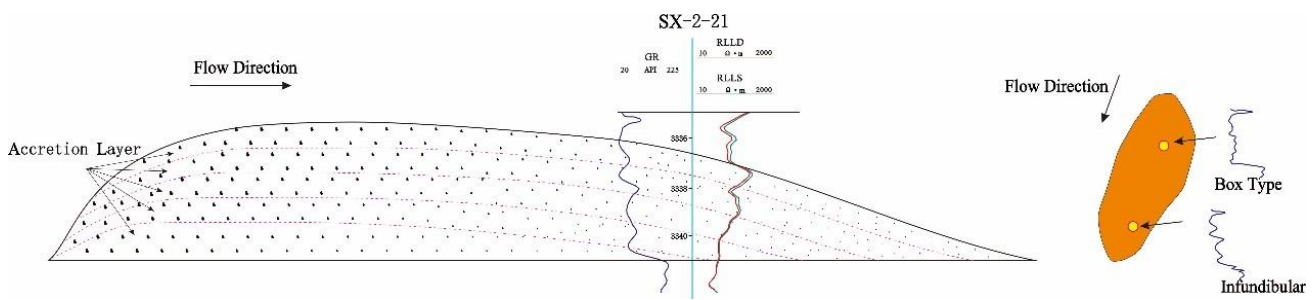

Figure 6-Logging curve morphology. 


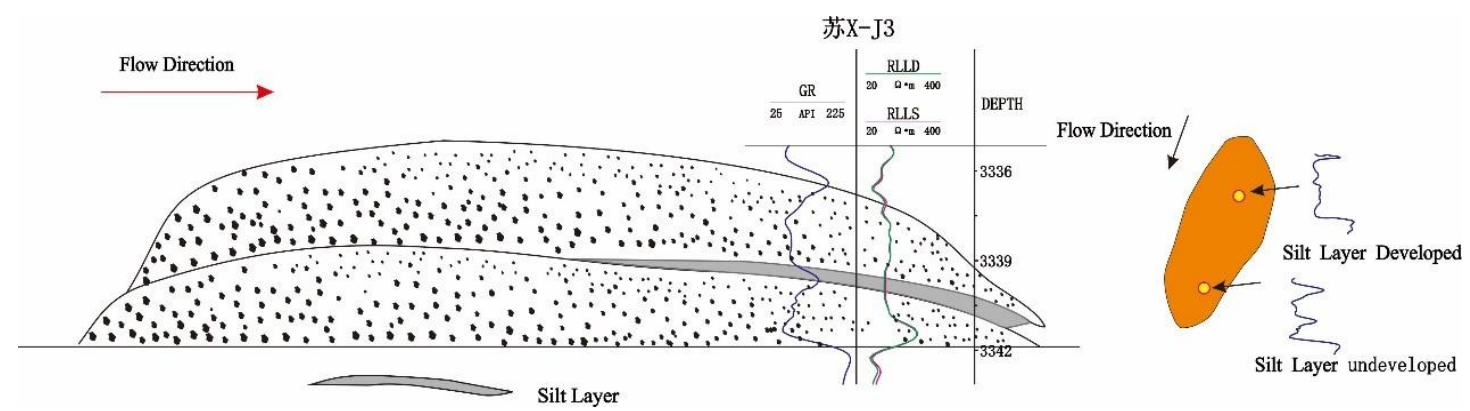

Figure 7-Silt layer development location.

Microfacies Overlay Characteristics. The sedimentation of the channel bar is mainly based on the vertical accretion and downstream accretion. Frequent lateral migration of the braided river causes different accretion layer in the lateral of channel bar. Individual wells show that the channel sandbodies is overlaid with channel bar sandbodies. This is a key mark to identify the edge of channel bar (Figure 8).

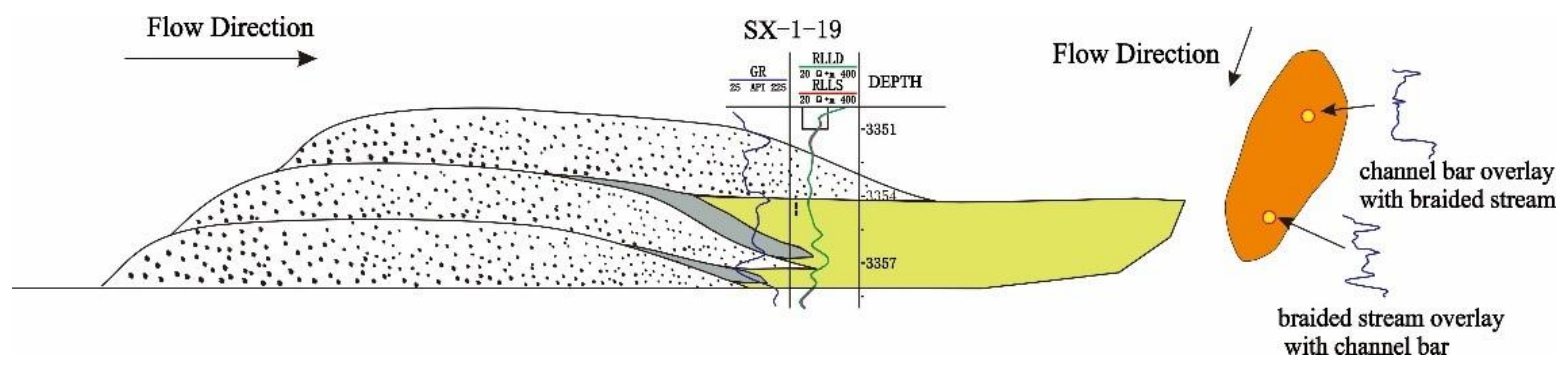

Figure 8-Microfacies overlay characteristics.

Single Sandbody Configuration Characteristics. Single sandbody characteristics show that the thickness of channel bar ranges from 3 to $5 \mathrm{~m}$, the width is $250 \sim 300 \mathrm{~m}$, the length is $500 \sim 900 \mathrm{~m}$. The width of braided river channel is usually less than $200 \mathrm{~m}$. The deposition pattern presents "alternate channel and bar, wide bar and narrow channel" on flat (Figure 9).

Control Effect of Reservoir Architecture on Effective Sandbodies. Five grade interfaces control the effective sandbodies distribution from the macro point of view. Considering the drilling situation, nearly all the effective sandbodies are distributed in the channel, partial channel downcutting, or lateral migration connected effective sandbodies that developed in different periods. The $4^{\text {th }}$ grade interface controls the distribution of channel bar and braided river in single channel. The different filling types of braided distributary channel decide the plane heterogeneity of single channel. Therefore, the distribution of effective sandbodies is affected. 


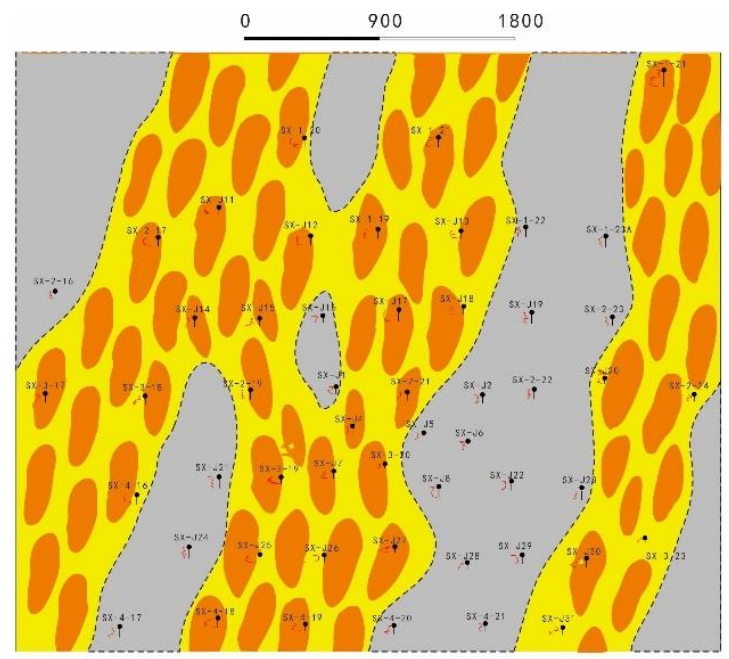

(a) Banded Channel

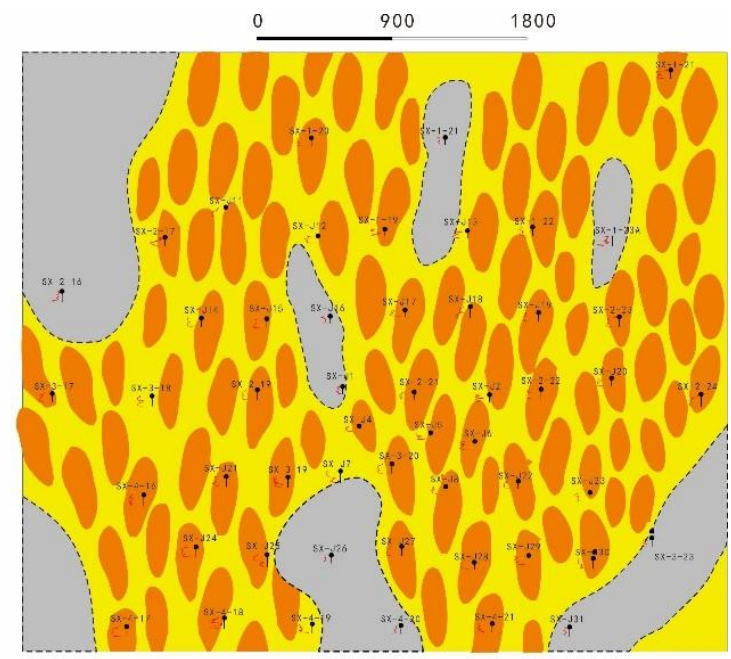

(b) Sheet Scale Channel

Channel

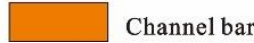

Interchannel

Figure 9-Silt layer development location.

The $4^{\text {th }}$ grade configuration profile shows that most effective sandbodies are distributed in the inter channel bar. And only a few sandbodies are distributed in the channel, which are identified as poor gas reservoirs. The discontinuous siltlayer developed in the $3^{\text {rd }}$ grade of inter channel bar can become an impermeable layer that prevents the fluid from flowing vertically to gas reservoir. The degree of influence relates to thickness and area. If thick and large sandbodies are distributed stably, the effective sandbodies are always in the bottom of channel bar (Figure 10).

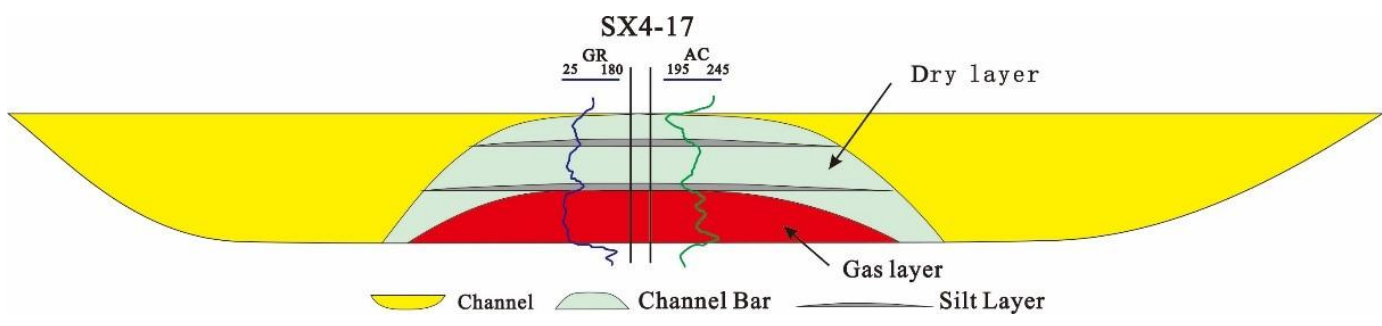

Figure 10-Control Effect of $3^{\text {rd }}$ grade interface.

\section{Conclusions}

The new methods were presented to characterize river channel sandbody spatial orientation by "changes on bottom of sandbody and microfacies overlay regular pattern", and channel bar sandbody spatial orientation by "logging cycle, silt layer position, and microfacies overlay characteristic". The reservoir structure analysis on river channel and channel bar was carried out.

There are two main plane combinations in the single channel sandbody of Shihezi group $8^{\text {th }}$ lower section in SuX adding area. The banded single channel, as a narrow band surrounded with interchannel mudstone, is $1000 \sim 2000 \mathrm{~m}$ wide. The sheet scale single channel is distributed as a sheet, interchannel mudstone is less developed, and the width of the channel is $1500 \sim 4000 \mathrm{~m}$.

The thickness of channel bar is usually $3 \sim 5 \mathrm{~m}$, the width is $250 \sim 300 \mathrm{~m}$, the length is $500 \sim 900 \mathrm{~m}$. The deposition pattern presents "alternate channel and bar, wide bar and narrow channel" on flat.

$5^{\text {th }}$ grade configuration unit controls macro distribution of effective sandbodies, $4^{\text {th }}$ grade configuration unit is the main control factor, $3^{\text {rd }}$ grade configuration unit has little effect on the distribution of effective sandbodies. The method has been successfully applied to optimize well location in Sulige gas field, and has reference value to the same type of reservoir configuration. 


\section{Acknowledgement}

National Science and Technology major projects "The development demonstration project of a large low permeability lithostratigraphic hydrocarbon reservoirs in Ordos Basin"(No. 2016ZX05050); PetroChina Company Limited Science and Technology major projects" Study on stable production and enhanced oil recovery technology in Changqing gas field"(No. 2016E-0509).

\section{Conflicts of Interest}

The author(s) declare that they have no conflicting interests.

\section{References}

Chen, Q., Zeng, M., Zhang, F., et al. 2004. Identification of Single Channel in Fluvial Reservoir and its Significance to the Oilfield Development. Petroleum Geology and Recovery Efficiency 11(3): 11-15.

Chen, F., Lu, T., Da, S., et al. 2008. Study on Sedimentary Facies of Braided Stream and Its Application in Geological Modeling in Sulige Gas Field. Petroleum Geology and Engineering 22(2): 22-24.

Corbeanu, R. M., Soegaard, K., and Szerbiak, R. B. 2001. Detailed Internal Architecture of a Fluvial Channel Sandstone Determined From Outcrop, Cores, and 3-D Ground-Penetrating Radar: Example From the Middle Cretaceous Ferron Sandstone, East-Central Utah. AAPG Bulletin 85(9):1583-1608

Bai, Z., Wang, Q., Du, Q., et al. 2009. Study on 3D-Architecturegeology Modeling and Digital Simulation in Meandering Reservoir. Acta Petrolei Sinica 30(6): 898-907.

Bai, Z. 2010. Study on the 3D Architecture Geological Modeling of Braided Fluvial Sandbody. Journal of Southwest Petroleum University (Science \& Technology Edition) 32(6):21-24.

Best, J. L., Ashworth, P. J., Bristow, C. S., et al. 2003. Three-Dimensional Sedimentary Architecture of a Large Mid-Channel Sand Braid Bar, Jamuna River, Bangladesh. Journal of Sedimentary Research 73(4): 516-530.

Ghazi, S. and Mountney, N. P. 2009. Facies and Architectural Element Analysis of a Meandering Fluvial Succession: the Permian Warchha Sandstone, Salt Range, Pakistan. Sedimentary Geology 221(3):99-126.

He, Z., Fu, J., Xi, S., et al. 2003. Geological Features of Reservoir Formation of Sulige Gas Field. Acta Petrolei Sinica 24(2): 6-12.

Jiao, Q., Gao, J., Hou, J., et al. 2009. Reservoir Architecture of Multiplex Glutenite on Alluvial Fan. Geological Science and Technology Information 28(6): 57-63.

Leeder, M. R. 1973. Fluvial Fining-Up Wards Cycles and the Magni- Tude of Paleochannels. Geology Magazine 110(3): 265-276.

Li, J. and Yang, X. 2009. Geological Characteristics of Gas Reservoirs in Well block 36-11 of Sulige Gas Field. Journal of Oil and Gas Technology 31(4): 62-65.

Li, S., Song, X., Jiang, Y., et al. 2011. Architecture and Remaining Oil Distribution of the Sandy Braided River Reservoir in the Gaoshangpu Oilfield. Petroleum exploration and development 38(4):474-481.

Liao, B., Zhang, W., Li, L., et al. 1998. Study on Modern Deposit of a Braided Stream and Facies Model: Taking the Yongding River as an Example. Acta Sedimentologica Sinica 16(1): 34-40.

Lin, Y., Wu, S., Yue, D., et al. 2013. Fine Anatomizing Reservoir Architecture of Fan-Delta Front: A Case Study on Dujiatai Reservoir in Shu 2-6-6 Block, Liaohe Oilfield. Natural Gas Geoscience 24(2): 335-344.

Liu, Z. and Jiao, Y. 1996. Genetic Facies of Meandering River and Its Spatial Distribution. Daqing Petroleum Geology and Development 15(3):6-9.

Liu, Y., Hou, J., and Song, B. 2011. Characterization of Interlayers within Braided-River Thick Sandstones: A Case Study on the Lamadian Oilfield in Daqing. Acta Petrolei Sinica 32(5): 836-840.

Lunt, I. A., Bridge, J. S., and Tye, R. S. 2004. A Quantitative, Three-Dimensional Depositional Model of Gravelly Braided Rivers. Sedimentology 51(3):377-414.

Lunt, I. A., Sambrook, S.G.H., Best, J.L., et al. 2013. Deposits of The Sandy Braided South Saskatchewan River: Implications for the Use of Modern Analogy in Reconstructing Channel Dimensions in Reservoir Characterization. AAPG Bulletin 97(4): 553-576.

Lynds, R. and Hajek, E. 2006. Conceptual Model for Predicting Mudstone Dimensions in Sandy Braided-River Reservoirs. AAPG Bulletin 90(8):1273-1288.

Ma, S. and Yang, Q. 2000. The Depositional Mode, 3-D Architecture and Heterogeneous Model of Point Bar in Meandering Channels. Acta Sedimentologica Sinica 18(2): 241-247

Ma, F., Zhang, S., and Wang, L. 2003. Sedimentary Characteristics and Microfacies of Fluvial Deposits of Mordern Nen River at Damagang Area. Journal of Daqing Petroleum Institute. 25(2): 8-11. 
Ma, S., Sun, Y., and Fan, G. 2008. The Method for Studying Thin Inter-Bed Architecture of Burial Meandering Channel Sandbody. Sedimentologica Sinica 26(4): 632-638.

Miall, A.D. 1985. Architectural-element Analysis: A New Method of Facies Analysis Applied to Fluvial Deposits. Earth Science Reviews 22(4): 261-308.

Miall, A. D. 1996. The Geology of Fluvial Deposits: Sedimentary Facies, Basin Analysis and Petroleum Geology. Berlin, Heidelberg: Springer.

Peakall, J., Ashworth, P. J., and Best, J. L. 2007. Meander-Bend Evolution, Alluvial Architecture, and the Role If Cohesion in Sinuous River Channels: a Flume Study. Journal of Sedimentary Research 77(3): 197-212.

Robinson, J. W. and Mccabe, P. J. 1997. Sandstone-Body and Shale-Body Dimensions in a Braided Fluvial System: Salt Wash Member (Morrison Formation), Garfield County, Utah. AAPG Bulletin 81(8): 1267-1291.

Skellya, R. L., Bristowb, C. S., and Ethridge, F. G. 2003. Architecture of Channel-Belt Deposits in an Aggrading Shallow Sandbed Braided River: the Lower Niobrara River, Northeast Nebraska. Sedimentary Geology 158(2):249-270.

Sun, T., Mu, L., and Zhao, G. 2014. Classification and Characterization of Barrier-Intercalation in Sandy Braided River Reservoirs: Taking Hegli Oilfield of Muglad Basin in Sudan as an Example. Petroleum exploration and development 41(1):112-119.

Sun, T., Mu, L., Wu, X., et al. 2014. A Quantitative Method for Architectural Characterization of Sandy BraidedRiver Reservoirs: Taking Hegli Oilfield of Muglad Basin in Sudan as an Example. Acta Petrolei Sinica 35(14): 715-724.

Wang, Y., Xu, X., Fu, X., et al. 2007. Research on the Sedimentary Facies Characteristics of Upper Paleozoic Reservoir in Su6 Region, Sulige Gas Field. Journal of Northwest University (Natural Science Edition) 37(2): 266-271.

Wen, H., Zheng, R., Gao, H., et al. 2007. Sedimentary Facies of the $8^{\text {th }}$ Member of Lower Shihezi Formation in Su6 Area, Sulige Gas Field. Sedimentologica Sinica 25(1): 90-97.

Wen, L., Wu, S., Wang Y, et al. 2011. An Accurate Method for Anatomizing Architecture of Subsurface Reservoir in Mouth Bar of Fluvial Dominated Delta. Journal of Central South University: Science and Technology Edition 42(4): 1073-1078.

Wu, S., Yue, D., Liu, J., et al. 2008. Hierarchy Modeling of Subsurface Palaeochannel Reservoir Architecture. Science in China: Series D: Earth Sciences 51(4): 126-137.

Wu, S. 2010. Reservoir Characterization \& Modeling. Beijing, China: Beijing Petroleum Industry.

Wu, S., Zhai, R., and Li, Y. 2012. Subsurface Reservoir Architecture Characterization: Current Status and Prospects. Earth Science Forntiers 19(2):15-23.

Wu, S., Ji, Y., Yue, D., et al. 2013. Discussion on Hierarchical Scheme of Architecture Units in Clastic Deposits. Geological Journal of China Universities 19(1): 12-22.

Xin, Z. 2008. Analysis on Architecture of Mouth Bar of Fluvial Dominated Delta. Geological Review 54(4): 527531.

Xing, B. 2014. Establishment of the Braided River Reservoir Geology Bank and Its Application: Daqing Changyuan Oilfiele La-Sa Piece of Pu I as an Example. Journal of Northeast Petroleum University 38(6):715724.

Yang, Y., Bao, H., Jia, Y., et al. 2008. Analysis on Control Factors of Sandstone Reservoir of the Upper Paleozoic in Ordos Basin. Journal of Palaeogeography 10(1): 25-32.

Yin, Z., Yu, X., and Lu, G. 2006. Sedimentary Facies of $8^{\text {th }}$ Member of Shihezi Formation in Block Su6 in Sulige Gas Field. Natural Gas Industry 26(3):26-27.

Yin, X., Peng, S., Li, H., et al. 2007. A New Micro-facies Study Method of Braid River Reservoir Based on Flow Unit. Geological Science and Technology Information 26(3): 26-27.

Yi, Z., Wu, S., Du, Q., et al. 2010. An Accurate Anatomizing Method for Structure of Reservoir of Allnvial Fan: A Case Study on Lower Karamy Formation, Liuzhong Area, Karamay Oilfield. Journal of Jilin University (Earth Science) 40(4): 940-945.

Zhang, C., Yin, T., Yu, C., et al. 2013. Reservoir Architectural Analysis of Meandering Channel Sandstone in the Delta Plain Based on the Depositional Process. Sedimentologica Sinica 31(4): 653-661.

Zhou, Y., Wu, S., Yue, D., et al. 2008. Recognizing Abandoned Channel with Underground Dense Well Pattern and Its Application in Sabei Oilfield. Journal of Oil and Gas Technology 30(4): 33-36.

Zhixin Ma is senior engineer of exploration and development of Changqing Oilfield Company. He mainly engaged in fine reservoir description, reservoir configuration characterization, horizontal well geological guidance and EOR research of Sulige tight sandstone gas reservoir. He holds a master degree in oil and gas field geological engineering from Daqing Petroleum Institute. 